Article

\title{
A Bibliometric Analysis of Energy Performance Contracting Research from 2008 to 2018
}

\author{
Wenjie Zhang ${ }^{1}$ and Hongping Yuan ${ }^{2, *(1)}$ \\ 1 School of Economics and Management, Southwest Jiaotong University, 111 North 1st Section of 2nd Ring \\ Road, Chengdu 610031, China \\ 2 School of Management, Guangzhou University, 230 Wai Huan Xi Road of Guangzhou Higher Education \\ Mega Center, Guangdong 510006, China \\ * Correspondence: hpyuan@gzhu.edu.cn
}

Received: 6 June 2019; Accepted: 22 June 2019; Published: 27 June 2019

\begin{abstract}
Increasing research interests in energy performance contracting (EPC) has resulted in a large number of publications over the past decade. However, very limited attempts have been made to map the global research in this area. To identify the state of the field and trends in EPC research, the VOSviewer software package was used to conduct a series of content analyses and examine global patterns among publications, including the distribution of core authors and institutions, high-frequency categories and keywords, journal and author contributions, highly cited papers, etc. Based on a systematical and deeply qualitative analysis on the 127 identified papers, five mainstream research topics in EPC were summarized, covering implementations of EPC, mechanisms for effective EPC projects, stakeholder behaviors and decisions in EPC projects, energy service company (ESCO) in EPC projects, and risk management in EPC. In addition, six main research gaps in EPC were identified, including lack of effective measurement and verification of energy savings, limited studies on EPC projects in the residential sector, ineffective mechanisms to ensure post-EPC energy-saving, limited research on the dual relationships among EPC project stakeholders, how to improve the energy users' (EU) attitudes/cognitions toward ESCO/EPC, and lack of effective mechanisms to prevent risks in EPC projects. Furthermore, based on the current EPC research topics and research gaps in EPC, six potential research directions in EPC in future were also explored, which are how to develop effective methods for measuring and verifying energy efficiency?, EPC diffusion issues in the residential sector, effective mechanisms to ensure post-EPC energy-saving, effects of cooperative and competitive relationships between EU and ESCO on the performance of EPC projects, how to improve the EU's attitudes/cognitions toward ESCO/EPC, and how to deal with risks in EPC projects. The outcomes would be useful for understanding the latest development of global EPC research and guiding future research in the subject.
\end{abstract}

Keywords: energy performance contracting; bibliometric analysis; VOSviewer; research trends

\section{Introduction}

In recent years, energy performance contracting (EPC) has attracted attention from global scholars regarding its market trends and acceptance [1-4]. For example, Li [5] made use of the analytic hierarchy process (AHP) fuzzy evaluation method to evaluate the financing problems in China's EPC projects; Lee and Dzeng [6] analyzed the whole market development of EPC in Hong Kong and Taiwan. Through a two-round Delphi study, Satu and Kirsi [7] carried out qualitative research in exploring the business model of EPC; Xu et al. [8] explored the main factors affecting the EPC in building energy efficiency retrofit in China's hotel industry through an analytic network process (ANP) model. Based on the questionnaire survey and interviews, Aasen et al. [9] analyzed critical factors affecting EPC and 
barriers to energy savings in the municipal sector in Norway; Polzin et al. [10] empirically studied EPC barriers in the retrofitting projects in German municipalities. All the above enriched the literature in the EPC field, which also challenged researchers in capturing an overview of the research trends and development. It became difficult to understand the research progress on EPC comprehensively, because the publications over the past few years have been increasing significantly. Therefore, it is essential to systematically examine the EPC literature, which can not only provide an in-depth understanding on the latest research development on the EPC subject, but also give a useful guide to inspire future research to improve EPC practice.

As one of the most critical methodologies, the literature review has been widely used to effectively show the research development in a field concerned. For example, Tsai and Wen [11] analyzed the journal articles published on science education, and promoted the whole international academic community to recognize the importance of this field. The literature review carried out by Flanagan et al. [12] provided a useful hand to other scholars in understanding the current development of the construction industry, and avoided the repetition and duplication of research efforts. Based on the publications from 2000 to 2009 in eight top international journals, Yuan and Shen [13] conducted a review on construction and demolition (C\&D) waste management, and analyzed the main authors' contributions, main research methods, and research topics, and forecasted the research trends of C\&D waste management. Mao et al. [14] reviewed the development of biomass energy during 1998 to 2013. The analysis contents of the journal articles, including authorship, institutions, and high-cited papers, showed the past and current state of the biomass energy research. Wang et al. [15] reviewed the whole development of waste-to-energy incineration. Through social network analysis, co-word analysis, and cluster analysis, those papers' relationships were explored, and five clusters were identified. In addition, with the tool of the structural equation model (SEM), Shang et al. [16] conducted a systemic review and explored the character differences among three main models (shared savings model, guaranteed saving model, chaffee model).

In this regard, we believe that it is essential to explore the research of EPC in recent years. The main aim of this paper is to identify and summarize the whole contexts of energy performance contract (EPC) related researches from 2008 to 2018 systemically. The work will be conducted to evaluate various published document characteristics, such as journals, research topics, research fields, high-cited scholars, high-cited papers, countries, and affiliations and so on. In addition, through bibliometric methods, the inner relationships among researchers, papers, affiliations, topics, and key words will also be shown clearly. Furthermore, based on the analysis of those published EPC papers, potential EPC research directions and trends will also be forecasted.

This paper is arranged as follows. In Section 2, we will provide a brief review of EPC, followed by an introduction of the research methodology adopted in Section 3. In Section 4, a discussion and analysis of the research results will be carried out, research topics, research gaps, and the research trends of EPC will also be identified and summarized. In the final section, we will reach the conclusions and present the limitations.

\section{A Brief of Research on Energy Performance Contracting}

According to the statements of Okay and Akman [17], EPC is an innovative financing technique and first came from the 1970s oil crisis. In fact, according to Zhou et al. [3], EPC is an energy efficient operation mechanism which improves energy efficiency by financing or providing energy saving technologies. In an EPC project, the cost of installation and management of energy saving equipment is mainly reduced by reducing energy consumption $[18,19]$. EPC is also a market mechanism or financing tool, encouraging building owners to carry out energy retrofits [2]. In EPC projects, the energy service company (ESCO) provides to the energy user (EU)/client a complete set of energy-saving products and services, such as energy audit, project financing, energy-saving designing, purchasing materials and equipment, and energy accounting $[3,20,21]$. However, different from the traditional benefit methods, 
ESCO revenues its inputs and benefits by sharing the benefits of energy-saving or cost saving with the EU together [1].

In fact, there are different operating models for EPC projects. According to Qin et al. [4], four EPC models were discussed, including the share savings model (SSM), the guaranteed saving model (GSM), the energy-cost trust model (ETM), and the finance lease model (FLM). On the other hand, Shang et al. [16] argued that EPC business models could be mainly divided into three styles, which are the shared savings model, guaranteed saving model, and chaffee model. No matter how many models the EPC models could be divided, it is agreed that two common EPC models are dominant, i.e., the share savings model (SSM) and guaranteed saving model (GSM). In SSM-EPC, ESCO provides the energy-saving services to the EU/client, and bears all the fees. As a reward, the EU must share the energy-saving benefits with the ESCO in a fixed ratio [4,22]. Different from SSM, in GSM-EPC, the ESCO must set a fixed expected energy-saving quantity clearly. Once the realistic energy-saving quantity cannot reach the expected level, the ESCO has to pay for the gap to offset the EU's expected energy-saving loss $[16,23]$. The operating differences mean that SSM is more popular in developing countries, such as China, and the GSM is more welcomed in developed countries, such as the US and Canada.

Besides EPC models, scholars have also paid attention to the development of the EPC market. In fact, the whole market of EPC is not coincident in the developing process. The EPC market of the USA has experienced rapid growth since 2000 due to incentive policies, EPC standards, and new funding sources [24]. However, the whole development of EPC in European and Asian regions is much slower, showing great variation in different countries $[25,26]$. In addition, the industries implementing EPC are varying in different countries. For example, in the US, Japan, Canada, Britain, Finland, and Australia, EPC is mainly used in building energy-efficiency retrofits $[2,7,10,23,24,27,28]$; whilst in China, EPC is more focused on the fields of coal, steel, and paper-making sectors [29].

As one of the critical parts of EPC, the energy service company (ESCO) always plays the most important role in the whole operating and managing process of EPC. It thus has been a long-standing topic in EPC. Painuly [30] analyzed the mechanism and obstacles of ESCO in developing countries. Based on the data of 38 countries, Vine [20] identified the whole development level of ESCO. Bertoldi et al. [31] assessed and evaluated the overall development of ESCO in European countries. Through an analysis of the energy data of 94 countries from 1981 to 2007, Fang et al. [32] proved that ESCO can reduce energy consumption effectively. Niko and Lasse [33] focused on the application of ESCO in Finland thermal energy enterprises. Kostka and Shin [34] investigated the ESCO market in China, and pointed out that the trust relationships between ESCO and the EU is the factor driving the smooth implementation of EPC projects. Deng et al. [35] discussed the issue of the energy-saving assessment and investment decision of ESCO in EPC projects. Zhou et al. [3] analyzed the competition and cooperation between ESCOs, and found that the healthy and orderly operation of ESCO ensured the smooth implementation and operation of EPC projects.

Various risks and uncertainties also exist, which impede the implementation of EPC projects. Sarkar and Singh [36] pointed out the great challenges of EPC in developing countries from financing aspects. In addition, financing problems in EPC were also focused on by Li [5]. Based on an AHP-fuzzy assessment method, $\mathrm{Li}$ [5] explored the financing bottleneck problems in five industries, including iron and steel, chemical, buildings, electricity, and energy. Besides, Hu and Zhou [37] revealed that engineering risks in EPC include the political and legal risk, technology risk, management risk, financial risk, project quality risk, and client risk. Furthermore, Qian and Guo [38] pointed out that the risks and uncertainties were from future energy price fluctuation, energy saving, unexpected accidents, and contract risks. In the research of Lee et al. [39], the critical risks in EPC projects were related to a possible payment default of EUs after installation, uncertainty of baseline measurement, and increase in installation costs in EPC. In addition, lack of awareness and cognition of EPC [40,41], technical barriers [6,8], the EU's negative attitude [6], and the missing of EPC policies and regulations [40,42] also limited the development and diffusion of EPC applications. 


\section{Research Methodology}

\subsection{Bibliometric Analysis Method}

Bibliometrics are a set of research methods to take the bibliometric characteristics and document system as the analysis object $[43,44]$, and provide an effective tool to carry out quantitative analysis in a specific research field $[45,46]$. Bibliometrics employ mathematical and statistical methods to explore various characteristics of documents, including distributed architecture, co-relationships, and varying patterns $[46,47]$. As one of the most effective and extensive quantitative methods, bibliometric analysis can measure the contribution of different aspects in a special research topic [48,49]. According to Zhou et al. [50], bibliometric analysis not only provides an effective tool to shift from the micro level to the macro level, but also can help scholars identify the research trends and popular problems in the future. Bibliometrics technology has been used extensively to carry out review-based studies in recent years. For example, Mao et al. [46] employed the bibliometric techniques to analyze the development of biomass energy; Wang et al. [15] conducted a bibliometric analysis on waste-to-energy incineration. In addition, bibliometric technology has also been used in other energy research fields, such as energy efficiency and solar energy [44]. The bibliometric method will also be used in this paper for carrying out a review of EPC research.

\subsection{Literature Screening}

A holistic study was adopted to summarize the latest research outputs (2008-2018) in the domain of EPC published in Web of Science (WoS). The identification of target papers was the first step, which is the basis of the discussion and analysis. The whole paper screening process included four steps mainly. Firstly, we inputted the topic of energy performance contracting or EPC into WoS, and set the time as 2008 to 2018 to limit the period of publication. Secondly, following the screening rule, we identified 1743 related papers, which covered various fields of science technology, social sciences, and arts humanities. Thirdly, based on the 1743 papers screened, we carried out the second round of literature screening. In the process, we classified 1743 papers, and found various literature types, including journal articles, books, conference articles, reviews, dissertations, and others. We only chose the 894 journal articles as samples for analysis in the second round of literature screening. Finally, based on the 894 identified papers, we carried out the third round of literature screening following the rule of TITLE-ABS-KEY, which was that a paper including 'energy performance contracting,' 'energy performance contract,' 'EPC,' 'energy service company,' or 'ESCO' in the title, abstract, or keywords was selected. This resulted in 127 identified papers. All the discussions and analysis in this paper is based on the 127 papers.

\subsection{The Analysis Tool: VOSviewer Software}

VOSviewer software, which was developed by Van and Waltman [43], has been commonly used to analyze and visualize bibliometric networks. It was adopted in this study as well. Distance-based visualizations of bibliometric networks can be provided by VOSviewer, which can show bibliometric visualizing networks and text mining features [43]. Based on bibliographic data, VOSviewer software can create various visualization maps, such as a co-authorship map, keyword co-occurrence map, citation map, bibliographic coupling map, or co-citation map [43]. Song et al. [51] used it to assist a literature review on the public-private-partnership (PPP) field; Zhao [52] and He et al. [53] applied it in the building information management (BIM) field; and Park and Nagy [54] used this technology to assist a review of the bibliographic data of building control.

According to Van and Waltman [43], in the visual map of VOSviewer, each circle represents a term, and the size of the circle and font represent the activity of the term. The larger the circle and font, the more active the term is in the field, and vice versa. The distance between any two terms in the diagram represents the degree of association between the two terms. The smaller the circle distance between the two terms, the stronger the correlation between the two terms, and vice versa. 


\section{Results, Analysis, and Discussion}

\subsection{Main Research Fields}

According to the statistics and classification of the 127 EPC papers, it was found that various research fields have been covered, such as energy, environment, engineering, business, and economic analysis. In this stage, paper classification was mainly carried out through screening the title, abstract, and keywords of papers. In fact, it was impossible to merely classify one paper into a specific field, because the paper might have explored some interdisciplinary issues within the EPC subject. For example, in Shang et al. [16,55], the main topic concerns energy field, but economic analysis was also an essential component for the analysis. The two papers were thus categorized into both the energy fuels and economic analysis fields. Following this rule, the top 10 fields in EPC research from 2008 to 2018 were identified (see Figure 1), covering a wide range of areas, such as energy fuels, environment science ecology, engineering, business economics, economic analysis, and construction building technology. It is clear that the three areas of the most publications are energy fuels (63 papers, 52.07\%), environment science ecology (47 papers, 38.84\%), and engineering (43 papers, 35.54\%). It was found that the total proportions of papers in all areas are above $100 \%$ because many papers are related to more than one area, confirming that research in EPC is highly interdisciplinary.

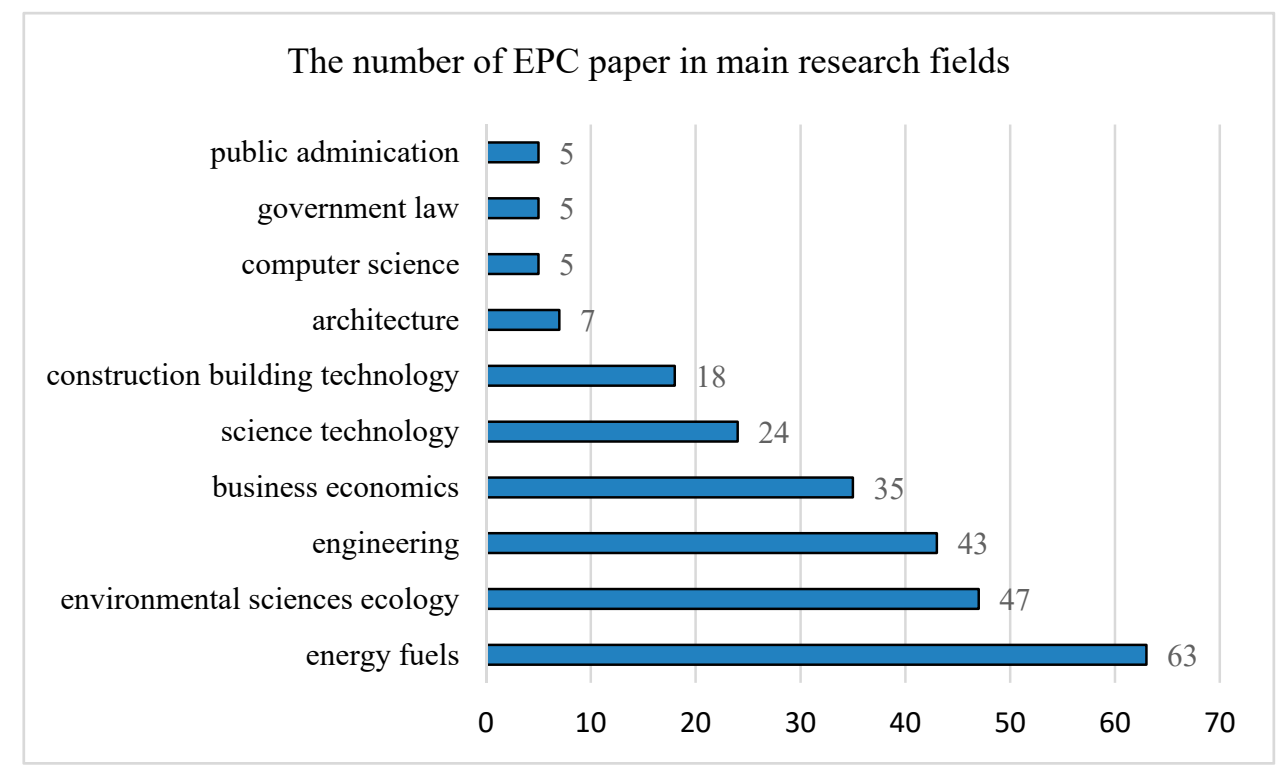

Figure 1. Top 10 fields in EPC research (2008-2018).

\subsection{Countries or Regions Active in EPC Research}

Although EPC has been a global concern, research intensity can vary in regions. Thus, it is important to demonstrate the distribution of EPC research globally through an analysis of papers published in different regions. This can also serve as an indicator to imply the demand of EPC in the regions concerned. It is easily observed from Figure 2. that as a representative of developing countries, China has been the most active in producing EPC studies over the last decade. Researchers from China contributed 59 papers, accounting for $46.46 \%$. This is understandable given the significant efforts of the Chinese government devoted to reducing energy consumption and saving resources across various industries (e.g., [2,3,5,8,42]. Researchers from the US contributed 21 papers, with a percentage of $16.54 \%$. The US has been a pioneer in carrying out EPC research (e.g., [17,18,36,56]. It was also shown that over the last decade, the European region contributed 32 papers in total. Based on the inter-connections among different countries, this proves that cooperation is prevailing in Europe when EPC research is conducted. 


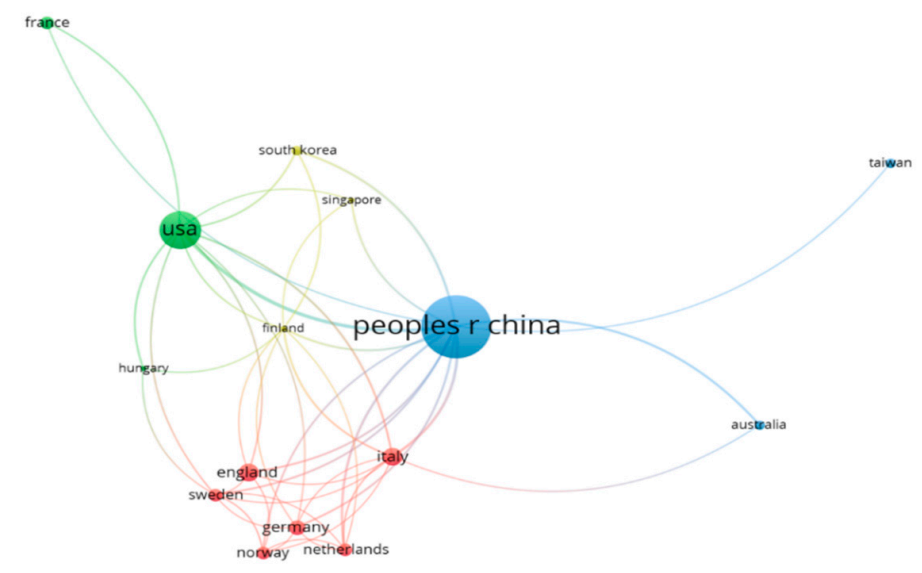

Figure 2. Network visualization of main countries or regions in EPC research.

\subsection{Main Journals Publishing EPC Research}

As discussed, the EPC subject can be related to different disciplines and thus papers appear in various journals. The journals publishing EPC papers were identified and analyzed through VOSviewer to inform significant journals broadcasting EPC research. The journal connections were visualized based on the number of papers published, the occurrence of keywords, and paper citations. The following rules should be noted when understanding the visualization outcomes in Figure 3. Firstly, the size of nodes and fonts in Figure 3. represents the frequency of the occurrence of keywords in the sample; thus, a larger node or font indicates a higher influence of the keyword in the network. Secondly, the more connections of a node exit, the more importance the node is given that a connection means a citation between the two papers connected; thus, nodes with more connections can be more important in the sample. Thirdly, the location of a node in VOSviewer was jointly determined by the frequency of occurrence, the number of citations, and its connections with other nodes; thus, a location approaching the center of the network means that the node is of vital importance to the network, and vice versa. Fourthly, the clusters by different colors and connections' lines indicate the closeness among journals in terms of mutual citations.

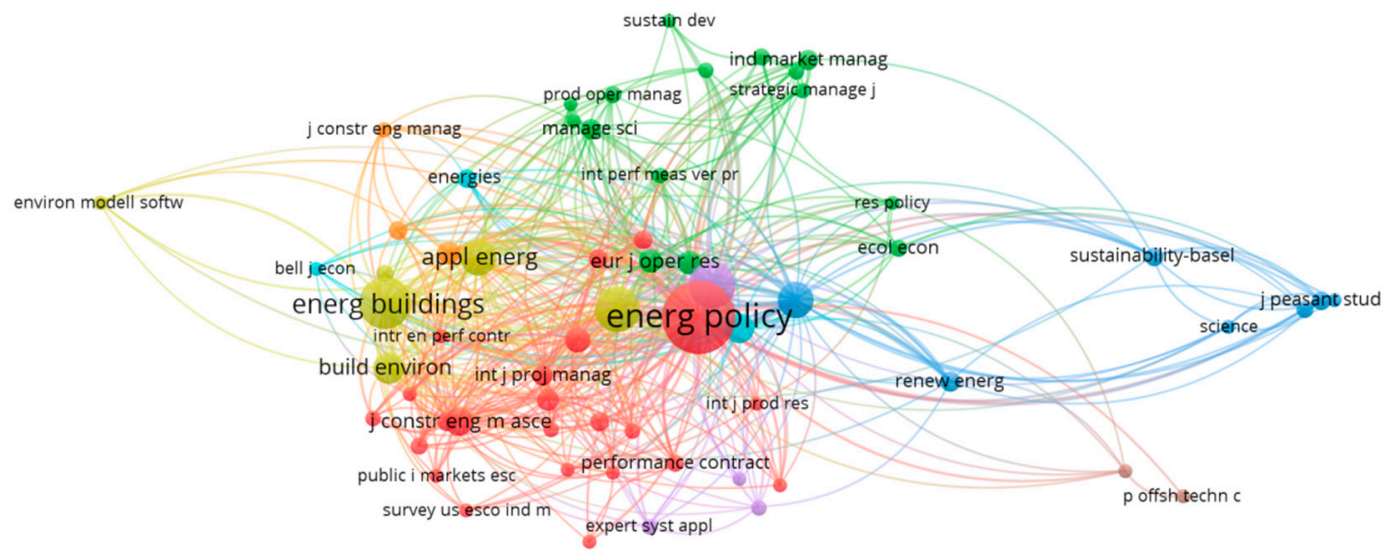

Figure 3. Network visualization of main journals publishing EPC research.

The minimum number of papers published was set at 1 . The analysis resulted in 63 journals identified, as shown in Figure 3. From the results, it is seen that the journals significantly contributing to EPC research include: Energy Policy (14 papers), Journal of Cleaner Production (13 papers), Energy and Buildings (10 papers), and Energy Efficiency (7 papers).

Also, the journals publishing EPC research can be generally classified into four clusters based on the node colors and distances, as shown in Figure 4. 


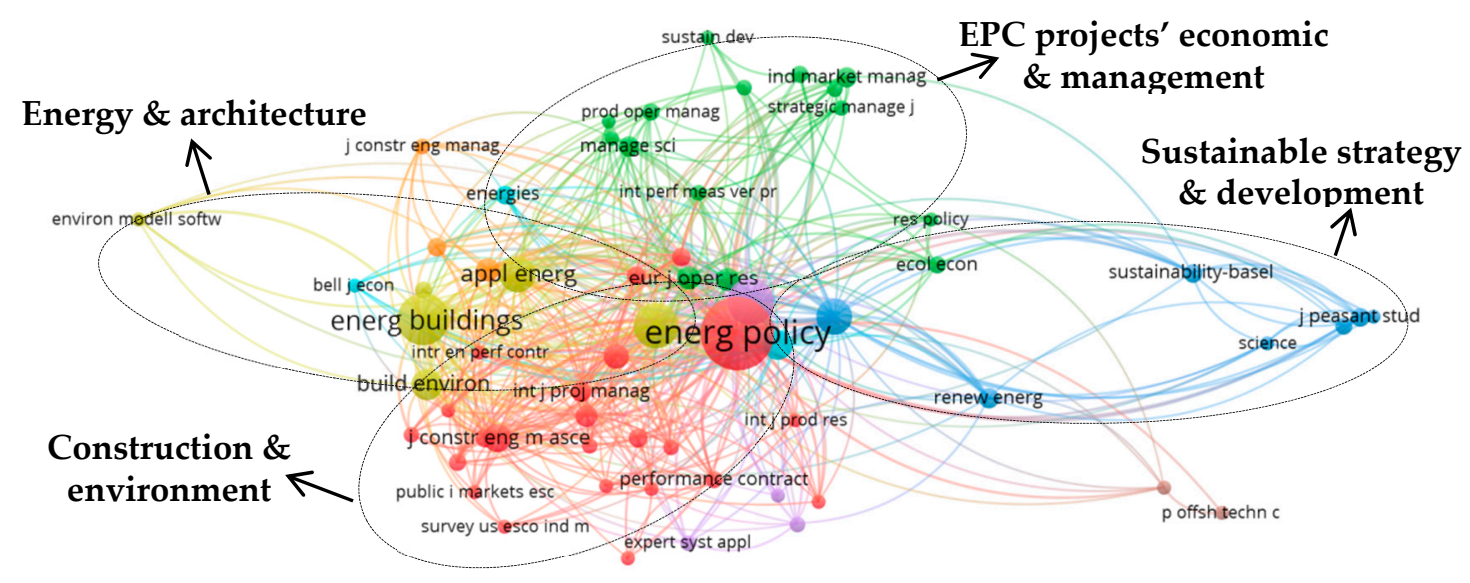

Figure 4. Four clusters of main journals publishing EPC research.

The core journals in the cluster of construction and the environment mainly include Energy Policy, Building and Environment, and the International Journal of Project Management. This cluster covers the largest number of journals and the distance among nodes is small, which implies that all of the journals have a unanimous research topic or research field. A detailed review of the papers in this cluster indicates that most of them focus on construction and environment problems, and we named the cluster as construction and environment. The journals, including Energy Buildings, Build Environment, Applied Energy, and Energy, form the cluster of energy and architecture. Most of the papers in this cluster concentrate on energy and architecture problems. The cluster of EPC projects' economic and management includes journals, such as the Journal of Environment Management, Production and Operations Management, and Sustainment Development. Most papers in this cluster explored EPC projects' economic and management issues. The cluster of sustainable strategy and development covers journals, such as Renewable Energy, and Sustainability. Those papers pay more attention to sustainable strategy and development problems. It is noted that there might be overlaps among two journal clusters. For example, it is clear that there is a great overlap between the cluster, construction and environment, and the cluster, energy and architecture, which is attributed to the interdisciplinary nature of the issues investigated.

\subsection{Main Affiliations in EPC Research}

From Table 1, it is clear that in the past decade, 13 institutions have published the most EPC studies, including (in descending order) 13 authors from Hong Kong Polytechnic University (e.g., Lam, P.T.I., and Lee, P.), 7 authors from City University of Hong Kong (e.g., Zhang, X.L.), 7 authors from Chongqing University (e.g., Xu, P.P.), and 6 authors from Tianjin University (e.g., Shang, T.C.). In addition, the United States Department of Energy Doe, Lawrence Berkeley National Laboratory, and Stanford University each contributed four researchers. The University of California Berkeley, University of Maryland College Park, University of Georgia, University of Sydney, Fudan University, and Huazhong University of Science and Technology owned three authors researching EPC. Overall, the analysis demonstrates the mainstream affiliations publishing EPC research are from China and the USA, which is closely related to the huge energy consumption of the two countries. To a large extent, pressing practical needs have been the main drivers for growing EPC research.

It is also apparent that the leading EPC papers are from the USA and China. The USA has long advocated for the concept and application of EPC since the 1970s because of the oil crisis. Also, the lasting and huge energy consumption in the country has significantly driven EPC research to explore more effective and reasonable energy-saving schemes. Although EPC has been applied in China for relatively few years, the strong driving force from the government is critical for its flourishing. For example, Chairman Xi emphasized the green economy and low-carbon notion about the whole economic and environment development of China in the future in the fifth meeting of the 18th CPC 
(the Communist Party of China) in October 2015, which was subsequently followed by national and regional governments in promoting green development, including EPC practices. This has provided a good basis for hastening EPC research.

Table 1. Main affiliations in EPC research (2008-2018).

\begin{tabular}{cccc}
\hline No. & Author Affiliation & Number of Authors & Regions \\
\hline 1 & The Hong Kong Polytechnic University & 13 & China \\
2 & City University of Hong Kong & 7 & China \\
3 & Chongqing University & 7 & China \\
4 & Tianjin University & 6 & China \\
5 & United States Department of Energy Doe & 4 & USA \\
5 & Lawrence Berkeley National laboratory & 4 & USA \\
5 & Stanford University & 4 & USA \\
8 & University of California Berkeley & 3 & USA \\
8 & University of Maryland, College Park & 3 & USA \\
8 & University of Georgia & 3 & USA \\
8 & University of Sydney & 3 & Australia \\
8 & Fudan University & 3 & China \\
8 & Huazhong University of Science and Technology & 3 & China \\
\hline
\end{tabular}

Note: only mainstream affiliations involving no less than three authors are listed.

\subsection{Analysis of Main Author Contributions}

In this chapter, an in-depth analysis of the retrieved publications reveals useful information for understanding the significant authors (author contributions and citations), influential papers, and productive institutions.

\subsubsection{Analysis of Productive Authors}

Through an analysis of the scholars authoring the 127 EPC papers, the most productive authors, including their connections of co-author networks, were identified. To a certain extent, an author's level of productivity can be representative of the devoted efforts of that researcher. For this analysis, the minimum number of papers published of an author was set at two. Overall, 28 authors met the criteria. The most high-productive authors were Xu, P.P. and Chan, E.H.W. with seven EPC papers each, followed by Lam, P.T.I. who contributed five papers.

Also, it is clear to see that all 28 authors can be divided into 5 clusters in Figure 5. We renamed each cluster with the name of a typical productive scholar. For example, the most influential research group is cluster Backlund, S., including the authors of Backlund, S., Chen, Z., Goldman, C.A., Larsen, P.H., Lee, S., Nolden, C., Qian, D., Shang, T.C., and Zhang. K. Different from the outcomes of Figure 4, it is interesting to see that there is not any overlap between any two clusters, indicating the relative independence of EPC research groups.

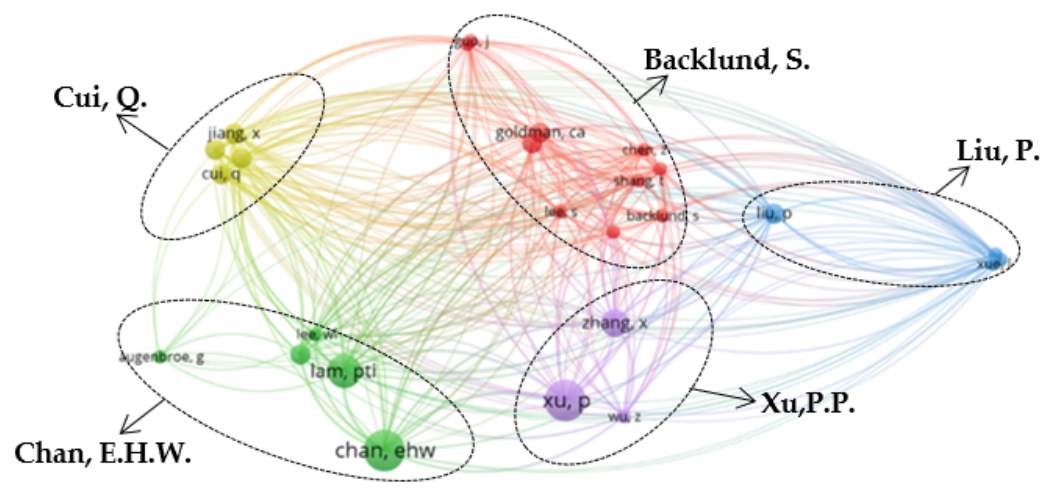

Figure 5. Coupling map of highly productive authors. 


\subsubsection{Analysis of Author Contributions}

Further, to quantitatively examine author contributions in EPC research, a method following Howard et al. [57] was applied for the analysis. This method has been popularly used for author contribution analysis in many disciplines, e.g., $[11,13,58]$. The formula used by the method for score calculation is listed as follows:

$$
S=\frac{1.5^{n-i}}{\sum_{i=1}^{n} 1.5^{n-i}}
$$

where $S$ denotes any author's contributing score in a paper, $n$ denotes the total number of authors in a paper, and $i$ denotes the author's order. In the formula, the total score of a paper is set as 1 . For example, if a paper has five authors, then the first author's contributing score is 0.38 , the second is 0.26 , the third is 0.17 , the fourth is 0.11 , and the last is 0.08 . The most common and possible author contributing score matrix is listed in Table 2.

Table 2. Multi-author's contribution score matrix for a specific paper.

\begin{tabular}{cccccccc}
\hline $\begin{array}{c}\text { Total Number } \\
\text { of Scholars }\end{array}$ & 1st & 2nd & 3rd & 4th & 5th & 6th & 7th \\
\hline 1 & 1.00 & & & & & & \\
2 & 0.60 & 0.40 & & & & & \\
3 & 0.47 & 0.32 & 0.21 & & & & \\
4 & 0.42 & 0.28 & 0.18 & 0.12 & & & \\
5 & 0.38 & 0.26 & 0.17 & 0.11 & 0.08 & & \\
6 & 0.37 & 0.25 & 0.16 & 0.10 & 0.07 & 0.05 & \\
7 & 0.35 & 0.24 & 0.16 & 0.10 & 0.07 & 0.05 & 0.03 \\
\hline
\end{tabular}

Following the formula above, 17 productive and high-cited authors' contributing scores were obtained (see Table 3). Each of them published more than 2 EPC papers and received more than 10 citations from peer-researchers over the past decade. In the analysis, the four measurements, including the number of published papers, contribution score, total citations, and average citations, were adopted to assess the performance of specific scholars. While some of the measurements were closely correlated to each other (such as the number of published papers and total citations), some may be independent (such as average citations), because a special scholar, who received the highest number of publications or total citations, might not be the highest in average citations.

Table 3. Productive and highly cited scholars.

\begin{tabular}{|c|c|c|c|c|c|}
\hline Scholars & $\begin{array}{c}\text { Number of } \\
\text { Published Papers }\end{array}$ & $\begin{array}{l}\text { Contribution } \\
\text { Score }\end{array}$ & $\begin{array}{c}\text { Total } \\
\text { Citations }\end{array}$ & $\begin{array}{l}\text { Average } \\
\text { Citations }\end{array}$ & Affiliations \\
\hline $\mathrm{Xu}$, P.P. & 7 & 2.64 & 161 & 23 & $\begin{array}{l}\text { The Hong Kong Polytechnic University } \\
\text { Chongqing University }\end{array}$ \\
\hline Chan, E.H.W. & 7 & 2.13 & 147 & 21 & $\begin{array}{l}\text { The Hong Kong Polytechnic University } \\
\text { The University of Sydney; Chongqing University }\end{array}$ \\
\hline Lam, P.T.I. & 5 & 1.69 & 34 & 7 & The Hong Kong Polytechnic University \\
\hline Lee, $P$. & 4 & 1.51 & 28 & 7 & The Hong Kong Polytechnic University \\
\hline Shang, T.C. & 4 & 1.39 & 11 & 3 & Tianjin University \\
\hline Deng, Q.L. & 4 & 1.26 & 37 & 9 & University of Maryland \\
\hline Larsen, P.H. & 3 & 1.07 & 41 & 14 & $\begin{array}{l}\text { University California Berkeley } \\
\text { Stanford University }\end{array}$ \\
\hline Zhang, X.L. & 3 & 0.95 & 28 & 10 & City University of Hong Kong \\
\hline Goldman, C.A. & 3 & 0.71 & 43 & 14 & University California Berkeley \\
\hline Jiang, X.L. & 3 & 0.68 & 37 & 12 & Fudan University \\
\hline Zhang, L.M. & 3 & 0.58 & 35 & 12 & $\begin{array}{c}\text { University of Maryland } \\
\text { Huazhong University of Science and Technology }\end{array}$ \\
\hline Cui, Q.B. & 3 & 0.48 & 37 & 12 & University of Maryland \\
\hline Backlund, S. & 2 & 0.88 & 93 & 47 & Linkoping University \\
\hline Wu, Z.Z. & 2 & 0.36 & 28 & 14 & The Hong Kong Polytechnic University \\
\hline Lee, W.L. & 2 & 0.42 & 17 & 9 & The Hong Kong Polytechnic University \\
\hline Guo, J.E. & 2 & 0.61 & 15 & 8 & Xi'an Jiaotong University \\
\hline Qian, D. & 2 & 0.92 & 15 & 8 & Xi'an Jiaotong University \\
\hline
\end{tabular}

Note: the scholars are ordered according to the number of published papers. 
It is easy to find that among all the scholars, both Xu, P.P. and Chan, E.H.W. were consistently ranked higher in terms of the number of published papers, total citations received, and average citations, indicating that the two scholars are both productive and influential in the research domain of EPC. Other scholars with significant contributions to the research area include Lam, P.T.I., Lee, P., Shang, T.C., Deng, Q.L., and Larsen, P.H., each of whom received a contributing score above 1. Besides, Table 3 also tells that the values of the four measurements are not always consistent. For example, although Lam, P.T.I ranked third in both the number of published papers and contribution score, his total citations and average citations were relatively lower compared with some other scholars, such as Larsen, P.H., Zhang, L.M., and Backlund, S.

\subsection{Highly Cited Papers in EPC Research}

The most highly cited 10 papers in EPC during the last decade are also summarized in Table 4 based on key parameters, including TC (total citations) and AC/Y (average annual citations since publication), with the minimum citations of 25. Consistent to the results in Table 3, Xu, P.P. and Chan, E.H.W have been jointly leading a series of studies that contribute significantly to EPC research ( 3 out of 10 selected articles). It is shown that the most highly cited paper is entitled 'Beyond barriers: A case study on driving forces for improved energy efficiency in the foundry industries in Finland, France, Germany, Italy, Poland, Spain, and Sweden' authored by Thollander, P., Backlund, S., Triannl, A., and Cagno, E., with 69 citations and the highest annual citations of 11.5. It was found in this paper that the whole energy efficiency potential was improved based on a questionnaire and a multiple case study in the European energy-intensive foundry industry, and that the ratio of samples using EPC to improve energy efficiency was about $25 \%$. The second highly cited article was 'Success factors of energy performance contracting (EPC) for sustainable building energy efficiency retrofit (BEER) of hotel buildings in China' published in Energy Policy in 2011, with 62 citations and an annual citations of 7.75. This study identified 21 critical factors affecting the success of EPC in hotel building energy-saving retrofit in China based on data from semi-structured interviews and a questionnaire survey. Furthermore, the researchers also explored the relative of the 21 factors through factor analysis. The third highly cited article is 'ANP model for sustainable Building Energy Efficiency Retrofit (BEER) using Energy Performance Contracting (EPC) for hotel buildings in China' published in Habitat International in 2013, with 42 citations and an annual citations of 7. In this paper, key performance indicators for BEER and critical success factors for EPC were identified through interviews and a questionnaire survey in the hotel industry in China. In addition, they developed an ANP model for BEER under EPC, and explored the main relationships among various dimensions, key performance indicators, and critical success factors, including significant authors (author contributions and citations), influential papers, and productive institutions.

Table 4. Top 10 highly cited EPC papers from 2008 to 2018.

\begin{tabular}{|c|c|c|c|c|c|c|}
\hline No. & Title of the Paper & Scholars & Journals & Year & TC & $\mathrm{AC} / \mathrm{Y}$ \\
\hline 1 & $\begin{array}{l}\text { Beyond barriers - A case study on } \\
\text { driving forces for improved energy } \\
\text { efficiency in the foundry industries in } \\
\text { Finland, France, Germany, Italy, Poland, } \\
\text { Spain, and Sweden }\end{array}$ & $\begin{array}{l}\text { Thollander, P.; } \\
\text { Backlund, S.; } \\
\text { Triannl, A.; } \\
\text { Cagno, E. }\end{array}$ & Applied Energy & 2013 & 69 & 11.5 \\
\hline 2 & $\begin{array}{l}\text { Success factors of energy performance } \\
\text { contracting (EPC) for sustainable } \\
\text { building energy efficiency retrofit (BEER) } \\
\text { of hotel buildings in China }\end{array}$ & $\begin{array}{l}\text { Xu, P.P.; } \\
\text { Chan, E.H.W.; } \\
\text { Qian, Q.K. }\end{array}$ & Energy Policy & 2011 & 62 & 7.75 \\
\hline 3 & $\begin{array}{l}\text { ANP model for sustainable Building } \\
\text { Energy Efficiency Retrofit (BEER) using } \\
\text { Energy Performance Contracting (EPC) } \\
\text { for hotel buildings in China }\end{array}$ & $\begin{array}{c}\text { Xu, P.P.; } \\
\text { Chan, E.H.W. }\end{array}$ & $\begin{array}{c}\text { Habitat } \\
\text { International }\end{array}$ & 2013 & 42 & 7 \\
\hline 4 & $\begin{array}{l}\text { New tool for promotion of energy } \\
\text { management and cleaner production on } \\
\text { no cure, no pay basis }\end{array}$ & Dobes, V. & $\begin{array}{l}\text { Journal of Cleaner } \\
\text { Production }\end{array}$ & 2013 & 35 & 5.83 \\
\hline
\end{tabular}


Table 4. Cont.

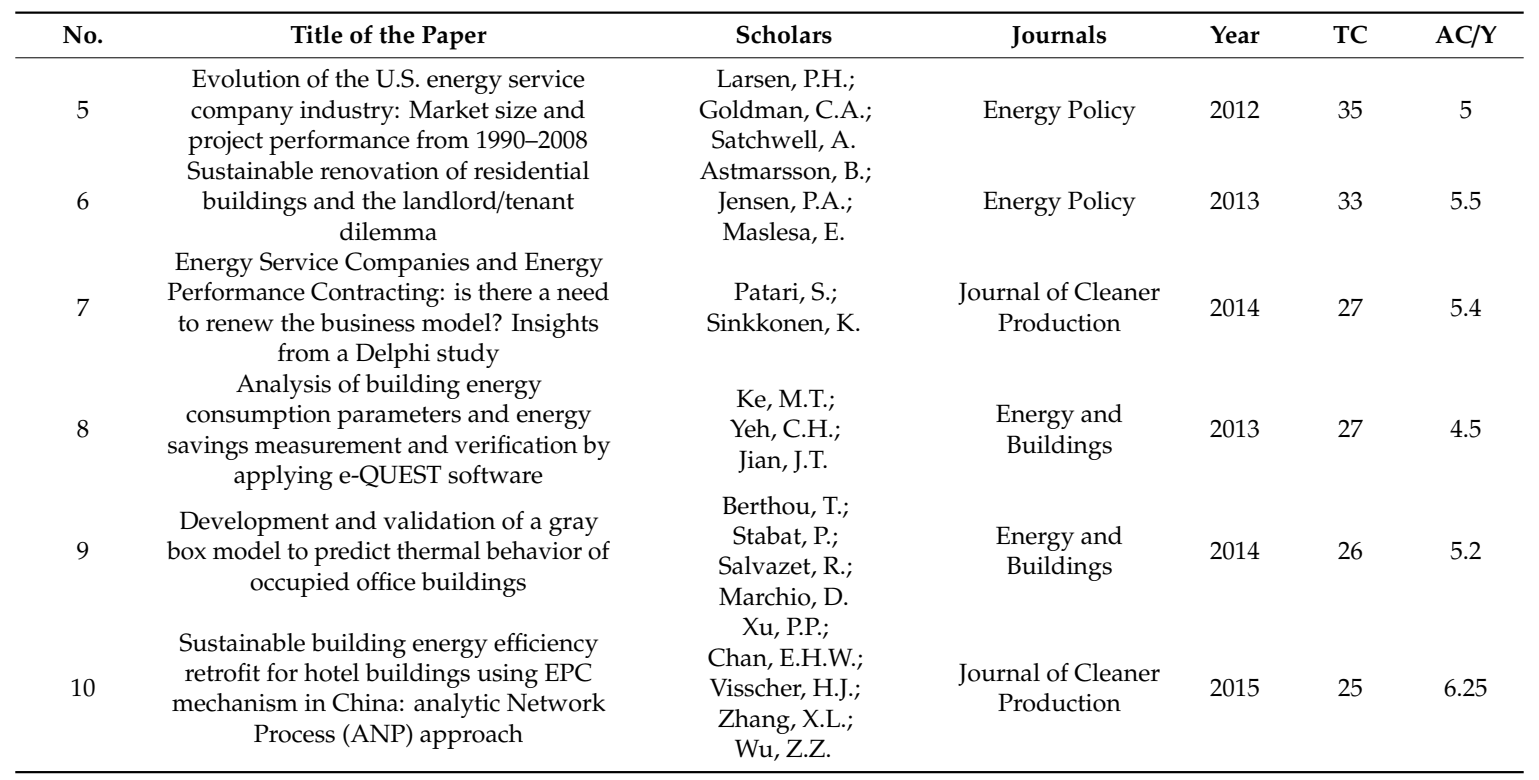

Note: TC: total citations; AC/Y: average annual citations since publication.

\subsection{Analysis of High-Frequency Keywords}

Keywords are used to highlight the central focus of a given paper and are useful for readers to learn its main researching contexts, e.g., [59]. Thus, keywords in the sample were also explored and analyzed by using the VOS-Viewer software to demonstrate the keywords with a high frequency as well as keyword relationships. The threshold of the keyword frequency was set at 2 and 66 out of 483 keywords were filtered, as described in Figure 6.

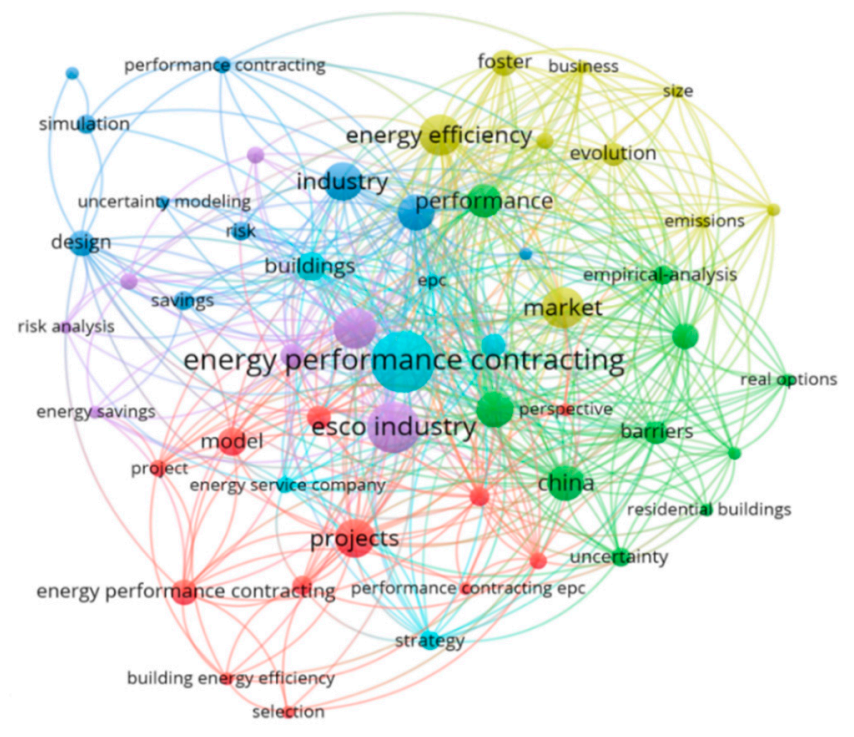

Figure 6. Network visualization map of high-frequency keywords.

Apparently, the core keyword of the sampled papers is energy performance contracting. The results also indicate several key topics attracting wide attention, which can be related to different dimensions, such as industry (i.e., ESCO industry, industry, barriers), performance (i.e., energy efficiency, building energy efficiency), research objects (i.e., projects, buildings, residential buildings), methods (empirical analysis, simulation, model), and countries (i.e., China). The interrelationships among those keywords 
are also visualized in the figure, which is helpful for understanding and reflecting EPC research topics over the past decade.

It is valuable to learn the evolution process of high-frequency keywords in EPC researches in the past decade, which would help researchers to possibly learn the main research trends. Hence, we constructed Figure 7 through VOSviewer software. In Figure 7, the time slots of different highlighted key words can be seen. The color of the circle describes the happened time slot clearly, with darker circlers indicating earlier highlighted key words. The three red dotted red lines show the high-frequency keywords' evolution process in the past years. For example, the color of the circle of building energy efficiency and selection is dark, following the color references in the bottom right corner of the figure, we can judge that those highlighted key words happened in about 2014, which implies that the researchers pay more attention to these topics in that time. Similarly, the highlighted key words, such as uncertainty, barriers, and real options happened in about 2016, which implies researchers' new focusing directions in EPC research.

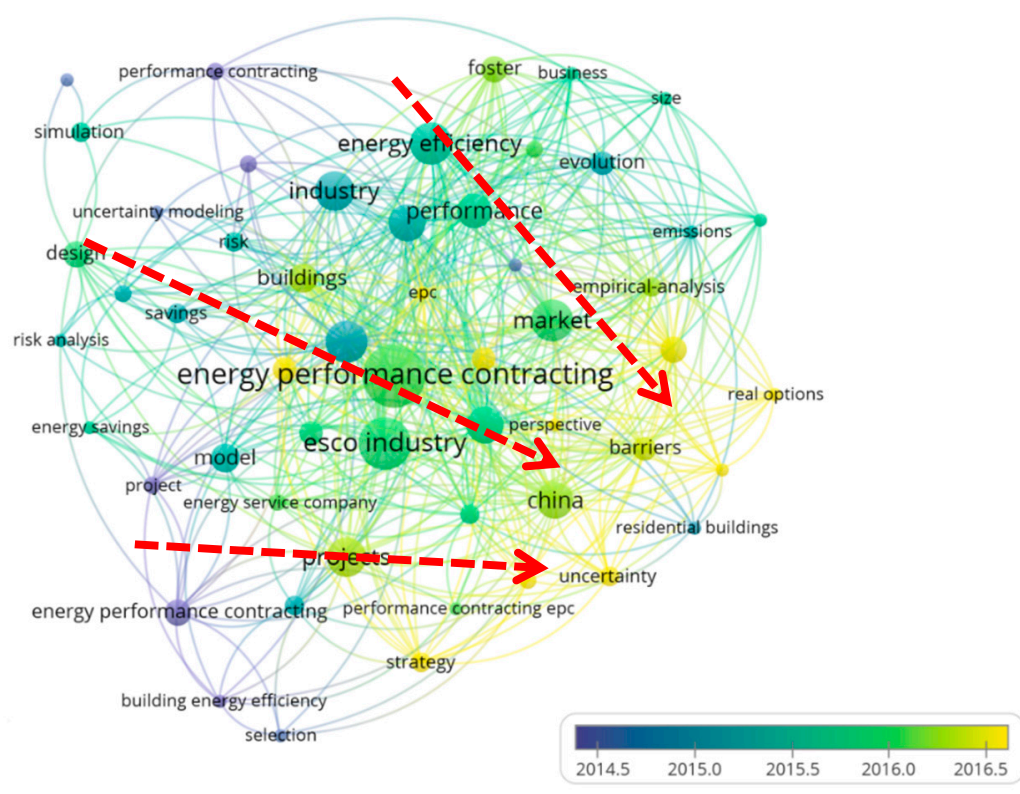

Figure 7. The overlay visualization map of high-frequency keywords.

\subsection{Research and Data Analysis Methods}

Research and data analysis methods are important in carrying out a scientific research. These are not only critical for evaluating the robustness of the research outcomes, but also helpful for understanding the evolution of the research in the domain concerned $[13,59,60]$. Thus, the research and analysis methods employed in the identified sample were analyzed. In line with the results, three research methods, mainly including theoretical analysis (43 papers, $33.85 \%$ ), empirical survey (39 papers, $30.71 \%$ ), and case study ( 45 papers, $35.44 \%$ ), were applied. Among them, the case study is the most commonly used method, followed by a theoretical analysis and empirical survey. It should be noted that herein, a case study refers to an examination of the status quo and barriers of EPC development, and the proposal of measures to enhance EPC applications based on a thorough analysis and discussion of realistic EPC cases/projects (e.g., [9,41,61-63]). Theoretical analysis is employed to examine the dynamic decision-making process among major stakeholders involving EPC projects, i.e., the ESCO, the EU, and the government, mostly based on the game theory (e.g., $[3,22,38,62,64,65])$. Data in such samples are all hypothesized based on an abstract of real-world EPC project practices. Also, studies focusing on the examination of EPC topics through the development of mathematical models through approaches, such as ANP, AHP, fuzzy set methods, and Monte Carlo, also exist (e.g., $[5,8,66,67])$. An empirical survey refers to studies using approaches, such as questionnaires, 
interviews, and site visits, to conduct surveys with EPC industry practitioners, in order to collect their opinions toward EPC issues (e.g., [1,10,24,33]).

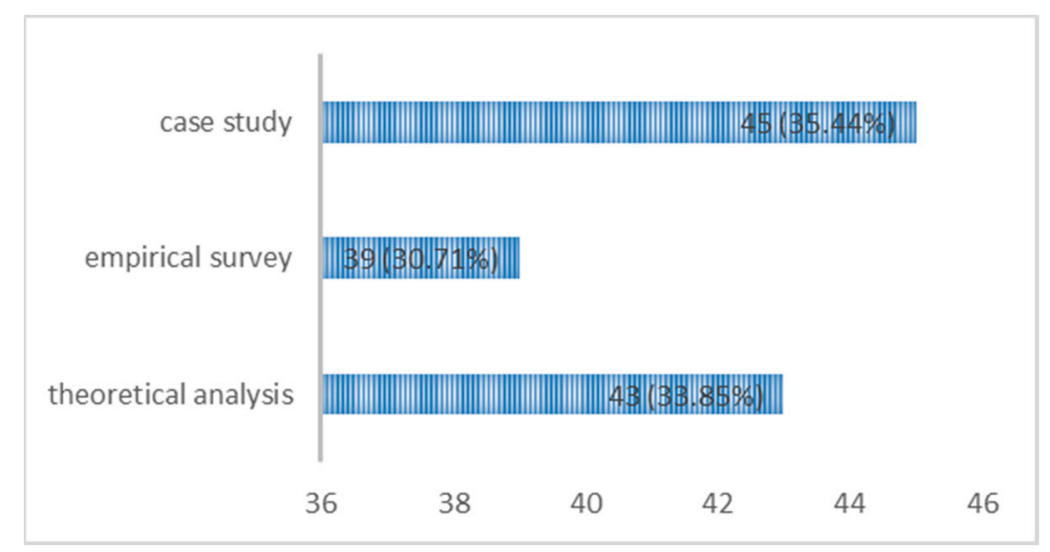

Figure 8. Three main research methods.

As for data analysis methods (Figure 9), modeling and simulation methods (45 papers, $35.44 \%$ ), descriptive analysis (41 papers, $32.28 \%$ ), statistical analysis (35 papers, $27.56 \%$ ), and cost-benefit analysis methods (6 papers, $4.72 \%$ ) were commonly used. Normally, modeling and simulation methods refer to performing data analysis with the aid of various modeling techniques and professional simulating software packages, such as analyzing interrelated relationships and decisions among major EPC stakeholders (e.g., $[3,4,38,62,68])$. Descriptive analysis is commonly used in studies aiming at identifying barriers and countermeasures for the EPC industry and projects. Data in these studies are always analyzed based on main statistical indicators, such as the mean value and standard deviation of the sampled data, which is critical for assessing the research hypothesis (e.g., [34,69-71]). Statistical analysis is facilitated by professional statistical analysis software, such as statistical product and service solutions (SPSS), aiming at deeper data analysis than descriptive analysis. Methods, such as factor analysis, principal component analysis, and regression analysis, are widely adopted for such analysis (e.g., [6,72]).

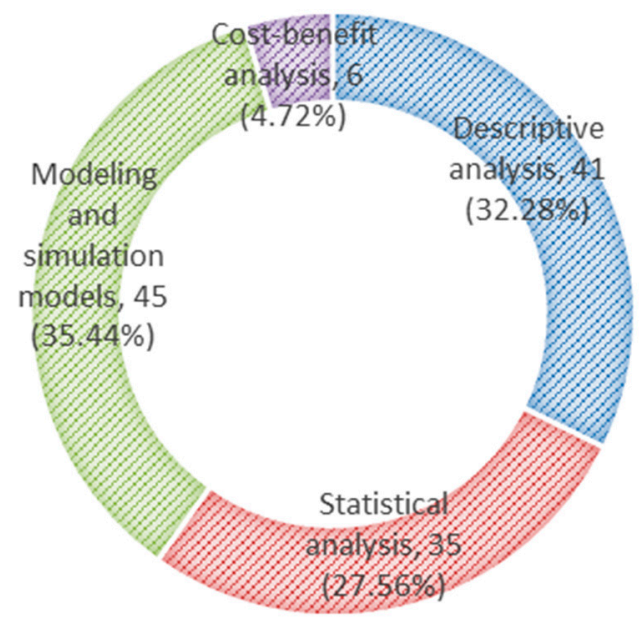

Figure 9. Four main data analysis methods.

\section{Discussion and Analysis of Current and Future Research Topics}

Besides the scientometric and statistical analysis above, the paper also carries out in-depth discussions about major EPC research topics over the past decade and explores potential research topics for the future. The discussions are based on the contents of the identified samples. 


\subsection{Research Topics in EPC Research}

\subsubsection{Implementations of EPC}

Since EPC was first adopted in the 1970s, how to implement EPC successfully in various sectors and countries has been a central topic. For example, Alessandro et al. [18] and Paolo et al. [41] investigated the energy-saving performance of EPC in acute hospital and community clinics, but Paolo et al. [41] focused on the evaluation of energy-saving quantity in EPC. Hufen and Bruijn [28] examined the energy-saving effect of EPC projects in public swimming pools. Through qualitative analysis of the whole development of EPC in China, Yuan et al. [42] pointed out that legal protection, policy guidance, and fiscal incentive are three main aspects. Based on the outcomes from a questionnaire survey and interviews, Zhang et al. [73] identified 10 critical success factors (CSFs) affecting the implementations of EPC in China, covering the local government energy policy, supports for EPC project financing, energy-saving evaluation standard, energy-saving equipment quality, and ESCO management quality. $\mathrm{Xu}$ et al. [2] and $\mathrm{Xu}$ and Chan [74] also identified the main factors affecting the implementation of EPC in China, but focused merely on hotel building energy efficiency retrofit (BEER) projects. Aasen et al. [9] and Polzin et al. [10] explored the EPC implementation in the municipalities of Norway and German, respectively. Although there have not been any studies providing effective measures for EPC implementation in different industries and countries, studies show that the social, economic, and environmental characteristics are critical in promoting EPC practices [75].

\subsubsection{Mechanisms for Effective EPC Projects}

Over the past decade, significant efforts have been focused on the mechanisms for effective EPC projects, which cover the evaluation of EPC project performance, contract management of EPC projects, and EPC business models. Generally, evaluation of EPC project performance helps project stakeholders to gain in-depth understanding about how to promote EPC projects. Lee and Dzeng [6] evaluated the whole situation of EPC projects in Hong Kong and Taiwan based on a dual-questionnaire survey and structured interviews. Among the various factors affecting EPC project performance, contract terms, such as the total inputs of an EPC project, the cost of capitals, the sharing ratios of participants, and the contract period, are critical [29]. In actual EPC project operations, different business models exist for contract design, such as the three EPC business models of the shared savings model (SSM), guaranteed saving model (GSM), and chaffee model (CM) claimed by Shang et al. [16]; the three EPC models of the shared savings model (SSM), guaranteed saving model (GSM), and outsourcing model (OM) proposed by Liu et al. [21]; and the EPC models of the share savings model (SSM), guaranteed savings model (GSM), energy-cost trust model (ECTM), and finance lease model (FLM) developed by Qin et al. [4]. Apparently, although with differences, SSM and GSM are widely recognized by scholars for developing EPC projects.

\subsubsection{Stakeholder Behaviors and Decisions in EPC Projects}

The energy user (EU) and energy service company (ESCO) have been regarded as two primary stakeholders in EPC projects and their behaviors and decisions are influential in the overall energy-saving performance. As a result, various theories and methods, such as the game theory, have been employed to investigate stakeholder behaviors and decisions. From the ESCO's perspective, Deng et al. [64] argued that the whole EPC cooperation between the EU and ESCO is a lasting and bargaining process, and thus they designed a model to assist the ESCO to balance the bidding competitiveness and the potential revenue loss. Shang et al. [55] explored the share of energy-saving benefits in EPC based on Rubinstein bargaining game theory, and identified the ESCO's optimal allocation duration and optimal proportion through the net present value (NPV) method. Besides the two-party game behaviors between the EU and ESCO, another participator exists (e.g., the local government), which should also be considered in assessing EPC project performance. In the study of Lu and Shao [68], 
the effect of government subsidy on EPC performance, and ESCO's pricing strategy were analyzed and discussed.

\subsubsection{ESCO in EPC Projects}

Many studies state that the performance of ESCO is decisive when evaluating the actual performance of EPC projects, because ESCO is directly involved in most of the operation and management activities in EPC projects. In this regard, studies on ESCO are significant in EPC research. For example, Bertoldi et al. [31] surveyed the whole operating and development status of ESCOs in European countries, and identified the main strategies to foster and improve ESCO's development. Based on the data of 94 countries from 1981 to 2007, Fang et al. [32] investigated the effect of ESCO activities on energy-saving and supported the argument that ESCOs improve energy efficiency. The study of Stuart et al. [76] focused more on the whole development of the ESCO industry, and provided a method to evaluate the whole size and market potential of the ESCO industry in the US. In addition, the whole operation and development situation of the Turkish ESCO market [69], Turkey ESCO market [77], Swedish ESCO market [78], and China ESCO market [79] were also discussed. Similar to EPC, there have also been various models for ESCO operation and management. According to Hannon and Ronan [23], three main ESCO business models exist, including the arm's-length model (ALM), concession agreement model (CAM), and community-owned run model (CORM). Furthermore, some scholars, e.g., Voronca and Voronca [80], explored ESCO diffusion problems to support effective development of the ESCO industry in the future.

\subsubsection{Risk Management in EPC}

Similar with other types of projects, uncertainties widely exist in EPC projects and bring project risks. The uncertainties may be related to various aspects, such as fluctuations of the future energy price, and an unpredictable accident and energy saving shortfall. The various risks can affect the overall energy-saving performance of EPC projects and thus attract research attention. Studies dealing with the risks of EPC projects cover various dimensions, including the identification of critical EPC project risks, risk evaluation, and risk and benefit analysis. For example, Zhang et al. [40] identified the main risks in EPC projects from the dimensions of government policy, financing environment, technology power, and client recognition. According to Hu and Zhou [37], EPC project risks in China are mainly related to the political and legal risk, technology risk, management risk, financing risk, project quality risk, and client risk. Shi et al. [66] summarized the six main risks of EPC projects in China and developed a fuzzy neural network model for risk evaluation. Differently, Lee et al. [39] explored risk management problems in EPC projects from the perspectives of ESCO and EU; they further stated that the main risks faced by ESCO include the EU's payment default after installation, uncertainty of baseline measurement, and additional increase of installation costs, and the risks focused on by the EU cover a possible long payback period, EPC project complexity, and the ESCO's operation ability.

\subsection{Current Research Gaps in EPC}

\subsubsection{Lack of Effective Measurement and Verification of Energy Savings}

Studies have proved the important role of EPC in improving the energy efficiency in various sectors, such as in the building retrofit field [2,8,74], real estate field [25,81,82], and in the iron system, steel system, and public light system $[3,83]$. However, how to effectively measure and verify $(\mathrm{M} \& \mathrm{~V})$ the energy-saving quantity achieved by EPC projects has been ignored, though some of the above studies (e.g., [2,25] acknowledged that M\&V is critical for EPC project implementation. In fact, it is very difficult to accurately $\mathrm{M} \& \mathrm{~V}$ the energy-saving quantity in EPC projects due to the vague parameters for measurement and verification in the current EPC industry [61]. Although scholars have made attempts to develop methods for evaluating the energy-savings of EPC projects (e.g., [82,84], how to develop a sophisticated $M \& V$ system remains a challenge. 


\subsubsection{Limited Studies on EPC Projects in Residential Sector}

Over the past decade, most of the EPC projects have been implemented in public and commerce institutions, such as the hotel sector $[8,85]$, hospital sector $[18,41]$, and municipal sector $[86,87]$. One important reason is that in those public and commerce sectors, there are relatively fewer decision-makers. As a result, the EU's attitudes and decisions toward EPC project development can be unified easily and enable the ESCO's energy retrofit activities. However, as for the residential sector, especially for multi-apartment buildings, various residents are involved and it is very difficult to achieve consistency regarding EPC project development in a short period. After all, their daily-life activities would be interrupted because ESCO needs sufficient time to measure, design, install, and tune the energy efficiency equipment. As revealed by Polzin et al. [10], Sinesilassie et al., [87], and Winther and Gurigard [70], not all residents would approve EPC project implementation although it can improve energy efficiency as a whole. In addition, the rebound effect (e.g., [88-90]) existing in current public and commerce EPC projects would be enlarged in the residential sector, which also limits the diffusion of EPC projects in the residential sector.

\subsubsection{Ineffective Mechanisms to Ensure Post-EPC Energy-Saving}

The quantity of energy-saving achieved by EPC projects is regarded as a core indicator to assess the overall performance of the project, and thus has been one of the central research topics over the last decade. Existing research contains distinct efforts of helping EPC project managers and ESCOs fulfill the expected energy-saving [38,91], or achieve the optimal benefits through EPC projects [35,55]. However, recent studies show that even the initially expected energy-saving is realized on the immediate complementation of an EPC project, whether the energy-saving performance is lasting is questionable. As Orea et al. [89] found, once the habit or live trace of a resident (EU) was disrupted or they feel their life becomes uncomfortable in post-EPC, the energy efficiency retrofit will be dropped or conflicted by the resident (EU). A subsequent study by Liu et al. [19] revealed similar concerns, stating that the EU's perceptions in post-EPC, which had been ignored by most researchers, was also critical in affecting the quantity of energy-saving achieved by EPC projects. Therefore, how to develop more effective mechanisms to ensure post-EPC energy-saving is still a challenge.

\subsubsection{Limited Research on the Dual Relationships among EPC Project Stakeholders}

In EPC project activities, various decision-making problems among project stakeholders are involved (e.g., $[27,35,40])$. Currently, the focus of games between main stakeholders (such as the EU and ESCO) is on the allocation of energy-saving benefits. For example, Shang et al. [55] analyzed how to allocate the EPC benefits between the EU and ESCO effectively, based on the Rubinstein bargaining model. A review of prior studies show that most of them pay attention to the cooperative relationship between the EU and ESCO (e.g., [22,62,64,65,92]), but ignore other relationship that may exist among the stakeholders. As Zhou et al. [3] argued, when two competitive manufacturers produce the same homogeneous product (e.g., steel, cement), the more energy-efficient manufacturer can provide the energy-saving retrofit service to the other through EPC model. In other words, two kinds of relationships exist between the two manufacturers, i.e., cooperation and competitive. The dual relationship makes the decision-making problems more complicated. On the one hand, the more energy-efficient manufacturer cooperates with the less energy-efficient manufacturer in EPC projects. On the other hand, they may compete with each other in the market. Thus, it calls for more studies on the decision-making problems under such a dual-relationship framework.

\subsubsection{How to Improve the EU's Attitudes/Cognitions toward ESCO/EPC}

Prior studies prove the important role of the EU's attitudes/cognitions in promoting EPC projects. According to Zhang et al. [40], one of the most critical factors limiting the diffusion of EPC in developing countries was the EU's negative attitudes toward EPC. Kostka and Shin [34] argued that an EPC project 
can be implemented smoothly only when the relationships between the EU and ESCO is good. Based on the comparative analysis of EPC in Hong Kong and Taiwan, Lee and Dzeng [6] found that the EU's terrible cognition to ESCO/EPC would hinder the development of the whole EPC industry. In addition, based on the survey of the ESCO industry in Sweden and EPC pilot projects in Norway, Soroye and Nilsson [78], and Winther and Gurigard [70] held arguments that the EU's attitudes/cognitions significantly affect the performance of EPC/ESCO. However, current studies show little evidence on how to effectively improve the EU's negative attitudes/cognitions toward ESCO/EPC.

\subsubsection{Lack of Effective Mechanisms to Prevent Risks in EPC Projects}

Uncertainties and risks are common and would significantly cause adverse effects on the overall performance of EPC projects. Therefore, over the past decade, efforts have been made to identify and evaluate risks in EPC projects (e.g., [37-39,61,66,67]). Questionnaire surveys and interviews are commonly used for collecting data and eliciting expert views on project risks and their influence (e.g., $[38,39,61])$, and the analytic hierarchy process (AHP), analytic network process (ANP), and fuzzy neural network (FNN) are adopted for quantitative risk evaluation (e.g., [37,66,67]). However, given the high frequency of the occurrence of project risks and the various dimensions of risks (such as human factor, energy price fluctuation, energy policy, force majeure) (e.g., earthquake, natural disaster, and war) (see $[61,66,67]$, it is difficult to effectively control and prevent such risks. Thus, lasting studies are suggested to deal with risks in EPC projects.

\subsection{Future Research Directions in EPC}

Based on the discussions above, six potential directions in future EPC research were identified and are summarized in Table 5.

- Effective methods should be developed to measure and verify $(\mathrm{M} \& \mathrm{~V})$ the quantity of energy-saving or the energy efficiency in EPC projects. Various characteristics should be considered in designing the M\&V methods or system, including (but not limited to) feasibility, accuracy, system, uniformity, and conciseness. The current gap in M\&V drives more EPC research focusing on this topic.

- It is believed that the diffusion of the EPC model in the residential sector would gain more and more research attention given the rapid development of urbanization $[26,84,93]$. Of course, the experience from EPC diffusion in the public and commerce sectors can provide useful guidelines to EPC diffusion in the residential sector.

- Ignorance of the EU's perceptions on post-EPC reduces people's satisfaction on EPC projects, although the energy-saving performance of EPC is good [19,89]. Also, effective mechanisms to ensure post-EPC energy-saving are critical in assessing the overall performance of EPC projects from a lifecycle perspective. Thus, more studies investigating the EU's perceptions on post-EPC as well as to ensure post-EPC energy-saving are desirable in the future.

- Consideration of both the cooperative and competitive relationships between the EU and ESCO significantly increases the complexity of the decision-making problems in EPC projects [3]. However, this point should be envisaged and examined in future EPC research, in order to optimize stakeholder decisions and reduce transaction costs in the implementation of EPC projects.

- Some EUs may hold negative attitudes or cognitions toward the implementation of EPC projects, which is identified as a primary barrier hindering the diffusion and development of EPC projects (e.g., $[6,40,70,78])$. Therefore, it is essential to effectively improve the EU's attitudes or cognitions toward ESCO/EPC for the promotion of EPC practices.

- Although the risks of EPC projects have been lastingly focused over the last decade (e.g., [37-39, $61,66,67])$, research gaps still exist on how to effectively handle the risks. Thus, it is suggested that more studies are desirable to develop more effective methods and perspectives for risk identification, evaluation, and management in EPC projects, such as an evaluation of the risks from a dynamic system perspective. 
Table 5. Future research directions in EPC.

\begin{tabular}{cc}
\hline No. & Potential Research Topics \\
\hline 1 & How to develop effective methods for measuring and verifying \\
2 & energy efficiency? \\
3 & EPC diffusion issues in the residential sector \\
4 & Effective mechanisms to ensure post-EPC energy-saving \\
5 & Effects of cooperative and competitive relationships between \\
6 & EU and ESCO on the performance of EPC projects \\
& How to improve EU's attitudes/cognitions toward ESCO/EPC \\
\end{tabular}

\section{Conclusions}

Based on the growing concerns on EPC, this paper provided a holistic view on the EPC research over the past decade. The analysis was mainly based on the results from a bibliometric analysis on 127 EPC-related papers published from 2008 to 2018. The scientometric analysis showed the following findings:

- Influential mainstream journals published research papers on EPC mainly cover Energy Policy, Journal of Cleaner Production, Energy and Buildings, and Energy Efficiency.

- According to the analysis result of the author's affiliation, researchers from some developed economies and regions, such as the US and Hong Kong, are the main contributors to EPC research. Besides, some developing economies (e.g., China) are carrying out the EPC research enthusiastically, due to its significant demand from practices.

- The co-author analysis results found that Xu, P.P. and Chan, E.H.W. are the top two productive and influential scholars in EPC research in the past decade. It is obvious that more and more research related to EPC would be conducted by scholars from those developing economies in the future, because EPC has become one of the most critical channels in achieving effective energy saving. By measuring the main authors' contributions, Xu, P.P. gained the highest contributing score, which implies his critical influence in the domain.

- An analysis of high-frequency keywords implies that the keywords, such as EPC, ESCO, energy efficiency, and building energy efficiency, have long been focused on by EPC researchers. The overlay visualization map of highlighted keywords also showed evolution trends and the direction of those highlighted keywords, which provides an effective guide to future EPC research.

- Three main research methods (theoretical analysis, empirical survey, and case study, data analysis) and four main data analysis methods (modeling and simulation methods, descriptive analysis, statistical analysis, and cost-benefit analysis) have been commonly applied in past EPC research.

The paper identified and summarized the main research topics in EPC research, which are the implementations of EPC, mechanisms for effective EPC projects, stakeholder behaviors and decisions in EPC projects, ESCO in EPC projects, and risk management in EPC. In addition, we also identified and summarized six main research gaps in EPC, including a lack of effective measurement and verification of energy savings, limited studies on EPC projects in the residential sector, ineffective mechanisms to ensure post-EPC energy-saving, limited research on the dual relationships among EPC project stakeholders, how to improve the EU's attitudes/cognitions toward ESCO/EPC, and a lack of effective mechanisms to prevent risks in EPC projects. Based on the current research topics and research gaps in EPC, six potential research EPC are proposed, which are how to develop effective methods for measuring and verifying energy efficiency, EPC diffusion issues in the residential sector, effective mechanisms to ensure post-EPC energy-saving, effects of cooperative and competitive relationships between the EU and ESCO on the performance of EPC projects, how to improve the EU's attitudes/cognitions toward ESCO/EPC, and how to deal with risks in EPC projects. 
The research findings can be useful and valuable for both scholars and practitioners in EPC field. As for EPC scholars, this paper can help them to learn the research development about EPC in the recent decade rapidly and effectively. In addition, the findings can guide scholars' future EPC research. For EPC practitioners, they can learn the latest EPC research by focusing on issues, and drawing lessons from them to improve the operation and management of EPC projects.

Author Contributions: W.Z. collected the data, carried out data analysis, and wrote the draft manuscript; H.Y. is the co-first coauthor, who designed the research procedure, analyzed the results, and reviewed and finalized the manuscript.

Funding: This research was funded by the National Natural Science Foundation of China (No. 71573216), the Sichuan Science and Technology Program (No. 2017ZR0150) and the Sichuan Province Cyclic Economy Research Center, (No. XHJJ-1807).

Conflicts of Interest: The authors declare no conflict of interest.

\section{References}

1. Marino, A.; Bertoldi, P.; Rezessy, S.; Boza, K.B. A snapshot of the European energy service market in 2010 and policy recommendations to foster a further market development. Energy Policy 2011, 39, 6190-6198. [CrossRef]

2. Xu, P.P.; Chan, E.H.W.; Qian, Q.K. Success factors of energy performance contracting (EPC) for sustainable building energy efficiency retrofit (BEER) of hotel buildings in China. Energy Policy 2011, 39, 7389-7398. [CrossRef]

3. Zhou, W.H.; Huang, W.X.; Zhou, S.X. Energy performance contracting in a competitive environment. Decis. Sci. 2017, 4, 723-765. [CrossRef]

4. Qin, Q.D.; Liang, F.Q.; Li, L.; Wei, Y.M. Selection of energy performance contracting business models: A behavioral decision-making approach. Renew. Sustain. Energy Rev. 2017, 72, 422-433. [CrossRef]

5. Li, Y. AHP-fuzzy evaluation on financing bottleneck in energy performance contracting in China. Energy Proc. 2012, 14, 121-126. [CrossRef]

6. Lee, P.; Dzeng, R.J. Current market development of energy performance contracting: A comparative study between Hong Kong and Taiwan. J. Prop. Invest. Financ. 2014, 32, 371-395. [CrossRef]

7. Satu, P.; Kirsi, S. Energy service companies and energy performance contracting: Is there a need to renew the business model? Insights from a Delphi study. J. Clean. Prod. 2014, 66, 264-271.

8. Xu, P.P.; Chan, E.H.W.; Henk, J.V.; Zhang, X.L.; Wu, Z.Z. Sustainable building energy efficiency retrofit for hotel buildings using EPC mechanism in China: Analytic Network Process (ANP) approach. J. Clean. Prod. 2015, 107, 378-388. [CrossRef]

9. Aasen, M.; Westskog, H.; Komeliussen, K. Energy performance contracts in the municipal sector in Norway: Overcoming barriers to energy savings? Energy Effic. 2016, 9, 171-185. [CrossRef]

10. Polzin, F.; Flotow, P.V.; Nolden, C. What encourages local authorities to engage with energy performance contracting for retrofitting? Evidence from German municipalities. Energy Policy 2016, 94, 317-330. [CrossRef]

11. Tsai, C.C.; Wen, M.C.L. Research and trend in science education from 1999 to 2002: A content analysis of publication in selected journal. Int. J. Sci. Educ. 2005, 27, 3-14. [CrossRef]

12. Flanagan, R.; Lu, W.S.; Shen, L.Y.; Jewell, C. Competitiveness in construction: A critical review of research. Const. Manag. Econ. 2007, 25, 989-1000. [CrossRef]

13. Yuan, H.P.; Shen, L.Y. Trend of the research on construction and demolition waste management. Waste Manag. 2011, 31, 670-679. [CrossRef] [PubMed]

14. Mao, G.Z.; Liu, X.; Du, H.; Zuo, J.; Wang, L.Y. Way forward for alternative energy research: A bibliometric analysis during 1994-2003. Renew. Sustain. Energy Rev. 2015, 48, 276-286. [CrossRef]

15. Wang, Y.; Lai, N.; Zuo, J.; Chen, G.Y.; Du, H.B. Characteristics and trends of research on waste-to-energy incineration: A bibliometric analysis, 1999-2005. Renew. Sustain. Energy Rev. 2016, 66, 95-104. [CrossRef]

16. Shang, T.C.; Zhang, K.; Liu, P.H.; Chen, Z.W. A review of energy performance contracting business models: Status and recommendation. Sustain. Cities Soc. 2017, 34, 203-210. [CrossRef]

17. Okay, N.; Akman, U. Analysis of ESCO activities using country indicators. Renew. Sustain. Energy Rev. 2010, 14, 2760-2771. [CrossRef] 
18. Alessandro, C.; Roberto, F.; Massimo, L.; Paolo, P. Managing energy retrofit of acute hospitals and community clinics through EPC contracting: The MARTE project. Energy Proc. 2015, 78, 1033-1038.

19. Liu, H.M.; Hu, M.Y.; Zhang, X.Y. Energy costs hosting model: The most suitable business model in the developing stage of energy performance contracting. J. Clean. Prod. 2018, 172, 2553-2566. [CrossRef]

20. Vine, E. An international survey of the energy service company (ESCO) industry. Energy Policy 2005, 33, 691-704. [CrossRef]

21. Liu, P.; Zhou, Y.; Zhou, D.K.; Xue, L. Energy performance contract models for the diffusion of green-manufacturing technologies in China: A stakeholder analysis from SMEs' perspective. Energy Policy 2017, 106, 59-67. [CrossRef]

22. Xing, G.Y.; Qian, D.; Guo, J.E. Research on the participant behavior selections of the energy performance contracting project based on the robustness of the shared savings contract. Sustainability 2016, 8, 730. [CrossRef]

23. Hannon, M.J.; Ronan, B. UK local authority engagement with the energy service company (ESCO) model: Key characteristics, benefits, limitations and considerations. Energy Policy 2015, 78, 198-212. [CrossRef]

24. Goldman, C.A.; Hopper, N.C.; Osborn, J.G. Review of US ESCO industry market trends: An empirical analysis of project data. Energy Policy 2005, 33, 387-405. [CrossRef]

25. Zhang, X.L.; Wu, Z.Z.; Feng, Y.; Xu, P.P. 'Turning green into gold': A framework for energy performance contracting (EPC) in China's real estate industry. J. Clean. Prod. 2015, 109, 166-173. [CrossRef]

26. Labanca, N.; Suerkemper, F.; Bertoldi, P.; Irrek, W.; Duplessis, B. Energy efficiency services for residential buildings: Market situation and existing potentials in the European Union. J. Clean. Prod. 2015, 109, $284-295$. [CrossRef]

27. Hannon, M.J.; Foxon, T.J.; Gale, W.F. The co-evolutionary relationship between energy service companies and the UK energy system: Implications for a low-carbon transition. Energy Policy 2013, 61, 1031-1045. [CrossRef]

28. Hufen, H.; Bruijn, H.D. Getting the incentives right. Energy performance contracts as a tool for property management by local government. J. Clean. Prod. 2016, 112, 2717-2729. [CrossRef]

29. Wu, Y.N.; Zhou, J.L.; Hu, Y.; Li, L.W.Y.; Sun, X.K. A TODIM-based investment decision framework for commercial distributed PV projects under the energy performance contracting (EPC) business model: A case in East-Central China. Energies 2018, 11, 1210. [CrossRef]

30. Painuly, J.P.; Park, H.; Lee, M.K.; Noh, J. Promoting energy efficiency financing and ESCO in developing countries: Mechanisms and barriers. J. Clean. Prod. 2003, 11, 659-665. [CrossRef]

31. Bertoldi, P.; Rezessy, S.; Vine, E. Energy service companies in European countries: Current status and a strategy to foster their development. Energy Policy 2006, 34, 1818-1832. [CrossRef]

32. Fang, W.S.; Miller, S.M.; Yeh, C.C. The effect of ESCOs on energy use. Energy Policy 2012, 51, 558-568. [CrossRef]

33. Niko, S.; Lasse, O. The Energy Services Company (ESCo) as business model for heat entrepreneurship-A case study of North Karelia, Finland. Energy Policy 2013, 61, 783-787.

34. Kostka, G.; Shin, K. Energy conservation through energy service companies: Empirical analysis from China. Energy Policy 2013, 52, 748-759. [CrossRef]

35. Deng, Q.L.; Jiang, X.L.; Zhang, L.M.; Cui, Q.B. Making optimal investment decisions for energy service companies under uncertainty: A case study. Energy 2015, 88, 234-243. [CrossRef]

36. Sarkar, A.; Singh, J. Financing energy efficiency in developing countries: Lessons learned and remaining challenges. Energy Policy 2010, 38, 5560-5571. [CrossRef]

37. Hu, J.R.; Zhou, E.Y. Engineering risk management planning in energy performance contracting in China. Syst. Eng. Proc. 2011, 1, 195-205.

38. Qian, D.; Guo, J.E. Research on the energy-saving and revenue sharing strategy of ESCOs under the uncertainty of the value of energy performance contracting projects. Energy Policy 2014, 73, 710-721. [CrossRef]

39. Lee, P.; Lam, P.T.I.; Lee, W.I. Risks in energy performance contracting (EPC) projects. Energy Build. 2015, 92, 116-127. [CrossRef]

40. Zhang, X.H.; Li, X.; Chen, S.L. Problem and countermeasure of energy performance contracting in China. Energy Procedia 2011, 5, 1377-1381.

41. Paolo, P.; Roberto, F.; Alessandro, C.; Massimo, L. Evaluation of energy conservation opportunities through energy performance contracting: A case study in Italy. Energy Build. 2016, 128, 886-899. 
42. Yuan, X.L.; Ma, R.J.; Zuo, J.; Mu, R.M. Towards a sustainable society: The status and future of energy performance contracting in China. J. Clean. Prod. 2016, 112, 1608-1618. [CrossRef]

43. Van, E.N.J.; Waltman, L. Software survey: VOSviewer, a computer program for bibliometric mapping. Scienometrics 2010, 84, 523-538. [CrossRef] [PubMed]

44. Du, H.; Li, N.; Brown, M.A.; Peng, Y.; Shuai, Y. A bibliographic analysis of recent solar energy literatures: The expansion and evolution of a research field. Renew. Energy 2014, 66, 696-706. [CrossRef]

45. Anthony, F.J.; Van, R. For your citations only? Hot topics in bibliometric analysis. Meas. Inter. Res. Pers. 2005, 3, 50-62.

46. Mao, G.Z.; Zou, H.Y.; Chen, G.Y.; Du, H.B.; Zuo, J. Past, current and future of biomass energy research: A bibliometric analysis. Renew. Sustain. Energy Rev. 2015, 52, 1823-1833. [CrossRef]

47. Dong, J.; Chi, Y.; Zou, D.; Fu, C.; Huang, Q.; Ni, M. Energy-environment- economy assessment of waste management systems from a life cycle perspective: Model development and case study. Appl. Energy 2014, 114, 400-408. [CrossRef]

48. Keiser, J.; Utzinger, J. Trends in the core literature on tropical medicine: A bibliometric analysis from 1952-2002. Scienometrics 2005, 62, 351-365. [CrossRef]

49. Bjurstrom, A.; Polk, M. Climate change and inter-disciplinarity: A co-citation analysis of IPCC third assessment report. Scienomtrics 2011, 87, 525-550.

50. Zhou, F.; Guo, H.C.; Ho, Y.S.; Wu, C.Z. Scientometric analysis of geostatistics using multivariate methods. Scienomtrics 2007, 73, 265-279. [CrossRef]

51. Song, J.; Zhang, H.; Dong, H. A review of emerging trends in global PPP research, analysis and visualization. Scienomtrics 2016, 107, 1111-1147. [CrossRef]

52. Zhao, X. A scientometric review of global BIM research, Analysis and visualization. Auto. Const. 2017, 80, 37-47. [CrossRef]

53. He, Q.; Wang, G.; Luo, L.; Shi, Q.; Xie, J.; Meng, X. Mapping the managerial areas of Building Information Modeling (BIM) using scientometric analysis. Int. J. Proj. Manag. 2017, 35, 670-685. [CrossRef]

54. Park, J.Y.; Nagy, Z. Comprehensive analysis of the relationship between thermal comfort and building control research-A data-driven literature review. Renew. Sustain. Energy Rev. 2018, 82, 2663-2679. [CrossRef]

55. Shang, T.C.; Zhang, K.; Liu, P.H.; Chen, Z.W.; Li, X.P.; Wu, X. What to allocate and how to allocate?-Benefit allocation in shared savings energy performance contracting projects. Energy 2015, 91, 60-71. [CrossRef]

56. Larsen, P.H.; Goldman, C.A.; Satchwell, A. Evolution of the U.S. energy service company industry: Market size and project performance from 1990-2008. Energy Policy 2012, 50, 802-820. [CrossRef]

57. Howard, G.S.; Cole, D.A.; Maxwell, S.E. Research productivity in psychology based on publication in the journals of the American Psychology Association. Am. Psychol. 1987, 42, 975-986. [CrossRef]

58. Leeuwen, T.; Costas, R.; Medina, C.C.; Visser, M. The role of editorial material in bibliometric research performance assessments. Scienometrics 2013, 95, 817-828. [CrossRef]

59. Jin, R.Y.; Yuan, H.P.; Chen, Q. Science mapping approach to assisting the review of construction and demolition waste management research published between 2009-2018. Resour. Conserv. Recycl. 2019, 140, 175-188. [CrossRef]

60. Volk, R.S.; Frank, J.S. Building Information Modeling (BIM) for existing buildings: Literature review and future needs. Autom. Constr. 2014, 38, 109-127. [CrossRef]

61. Lee, P.; Lam, P.T.I.; Yik, F.W.H.; Chan, E.H.W. Probabilistic risk assessment of the energy saving shortfall in energy performance contracting projects-A case study. Energy Build. 2013, 66, 353-363. [CrossRef]

62. Deng, Q.L.; Jiang, X.L.; Cui, Q.B.; Zhang, L.M. Strategic design of cost savings guarantee in energy performance contracting under uncertainty. Appl. Energy 2015, 139, 68-80. [CrossRef]

63. Satu, P.; Salla, A.; Ari, J.; Satu, V.; Anssi, S. Enabling and hindering factors of diffusion of energy service companies in Finland-results of a Delphi study. Energy Effic. 2016, 9, 1447-1460.

64. Deng, Q.L.; Zhang, L.M.; Cui, Q.B.; Jiang, X.L. A simulation-based decision model for designing contract period in building energy performance contracting. Build. Environ. 2014, 71,71-80. [CrossRef]

65. Lu, Y.J.; Zhang, N.; Chen, J.Y. A behavior-based decision-making model for energy performance contracting in building retrofit. Energy Build. 2017, 156, 315-326. [CrossRef]

66. Shi, H.; Niu, D.X.; Wang, H.M. Study of energy performance contracting project risk based on fuzzy neural network. Future Control. Autom. 2012, 173, 373-381.

67. Maria, G.S.; Reinhard, M. AHP-based risk analysis of energy performance contracting projects in Russia. Energy Policy 2016, 97, 559-581. 
68. Lu, Z.J.; Shao, S. Impacts of government subsidies on pricing and performance level choice in energy performance contracting: A two-step optimal decision model. Appl. Energy 2016, 184, 1176-1183. [CrossRef]

69. Akman, U.; Okay, E.; Okay, N. Current snapshot of the Turkish ESCO market. Energy Policy 2013, 60, $106-115$. [CrossRef]

70. Winther, T.; Gurigard, K. Energy performance contracting (EPC): A suitable mechanism for achieving energy savings in housing cooperatives? Results from a Norwegian pilot project. Energy Effic. 2017, 10, 577-596. [CrossRef]

71. Ren, R.; Zhou, H.; Hu, Z.; He, S.Y.; Wang, X.L. Statistical analysis of fire accidents in Chinese highway tunnels 2000-2016. Tunn. Undergr. Sp. Tech. 2019, 83, 452-460. [CrossRef]

72. Ruan, H.Q.; Gao, X.; Mao, C.X. Empirical study on annual energy-saving performance of energy performance contracting in China. Sustainability 2018, 10, 1666. [CrossRef]

73. Zhang, M.S.; Wang, M.J.; Jin, W.; Chun, X.B. Managing energy efficiency of building in China: A survey of energy performance contracting (EPC) in building sector. Energy Policy 2018, 114, 13-21. [CrossRef]

74. Xu, P.P.; Chan, E.H.W. ANP model for sustainable building energy efficiency retrofit (BEER) using energy performance contracting (EPC) for hotel building in China. Habitat Int. 2013, 37, 104-112. [CrossRef]

75. Li, Y.; Qiu, Y.; Wang, Y.D. Explaining the contract terms of energy performance contracting in China: The importance of effective financing. Energy Econ. 2014, 45, 401-411. [CrossRef]

76. Stuart, E.; Larsen, P.H.; Goldman, C.A.; Gilligan, D. A method to estimate the size and remaining market potential of the US ESCO (energy service company) industry. Energy 2014, 77, 362-371. [CrossRef]

77. Okay, E.; Okay, N.; Konukman, A.E.S.; Akman, U. Views on Trukey's impending ESCO market: Is it promising? Energy Policy 2008, 36, 1821-1825. [CrossRef]

78. Soroye, K.L.; Nilsson, L.J. Building a business to close the efficiency gap: The Swedish ESCO experience. Energy Effic. 2010, 3, 237-256. [CrossRef]

79. Gao, X.; Zhang, S. A research on barriers and strategies of development of Chinese ESCO. Constr. Econ. 2010, 10, 110-113.

80. Voronca, M.M.; Voronca, S.L. Sustainable energy technologies and local authorities: Energy service company, energy performance contract, forfeiting. J. Sustain. Energy 2013, 4, 1224-1231.

81. Zeng, R.C.; Chini, A.; Srinivasan, R.S.; Jiang, P. Energy efficiency of smart windows made of photonic crystal. Int. J. Constr. Manag. 2017, 17, 100-112. [CrossRef]

82. Pelin, G.B.; Anumba, C.J.; Leicht, R.M. Advanced energy retrofit projects: Cross-case analysis of integrated system design. Int. J. Constr. Manag. 2018, 18, 453-466.

83. Lee, P.; Lam, P.T.I.; Lee, W.L. Performance risks of lighting retrofit in energy performance contracting projects. Energy Sustain. Dev. 2018, 45, 219-229. [CrossRef]

84. Ghjuvan, A.F.; Laurent, M.; Rania, M. Uncertainty quantification for energy savings performance contracting: Application to an office building. Energy Build. 2017, 152, 61-72.

85. Xu, P.P.; Chan, E.H.W.; Lam, P.T.I. A conceptual framework for delivering sustainable building energy efficiency retrofit using the energy performance contracting (EPC) in China. J. Green Build 2013, 8, 177-190. [CrossRef]

86. Jensen, J.O.; Nielsen, S.B.; Hansen, J.R. Greening public buildings: ESCO Contracting in Danish municipalities. Energies 2013, 6, 2407. [CrossRef]

87. Sinesilassie, E.G.; Tabish, S.Z.S.; Jha, K.N. Critical factors affecting cost performance: A case of Ethiopian public construction projects. Int. J. Constr. Manag. 2018, 18, 108-119. [CrossRef]

88. Schleich, J.; Mills, B.; Dütschke, E. A brighter future? Quantifying the rebound effect in energy efficient lighting. Energy Policy 2014, 72, 35-42. [CrossRef]

89. Orea, L.; Llorca, M.; Filippini, M. A new approach to measuring the rebound effect associated to energy efficiency improvements: An application to the US residential energy demand. Energy Econ. 2015, 49, 599-609. [CrossRef]

90. Gillingham, K.; Rapson, D.; Wagner, G. The rebound effect and energy efficiency policy. Rev. Environ. Policy 2016, 10, 68-88. [CrossRef]

91. Lee, P.; Lam, P.T.I.; Lee, W.L.; Chan, E.H.W. Analysis of an air-cooled chiller replacement project using a probabilistic approach for energy performance contracts. Appl. Energy 2016, 171, 415-428. [CrossRef] 
92. Giretti, A.; Vaccarini, M.; Casals, M.; Macarulla, M.; Fuertes, A.; Jones, R.V. Reduced-order modeling for energy performance contracting. Energy Build. 2018, 167, 216-230. [CrossRef]

93. Ren, H.B.; Zhou, W.S.; Gao, W.J.; Wu, Q. Promotion of energy conservation in developing countries through the combination of ESCO and CDM: A case study of introducing distributed energy resources into Chinese urban areas. Energy Policy 2011, 39, 8125-8136. [CrossRef]

(C) 2019 by the authors. Licensee MDPI, Basel, Switzerland. This article is an open access article distributed under the terms and conditions of the Creative Commons Attribution (CC BY) license (http://creativecommons.org/licenses/by/4.0/). 